\title{
AUTORIA COLETIVA EM AMBIENTE INFORMATIZADO NO ENSINO SUPERIOR DE QUÍMICA
}

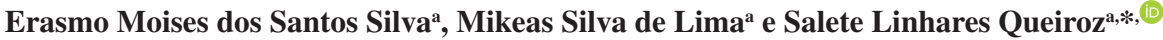 \\ anstituto de Química de São Carlos, Universidade de São Paulo, 13560-970 São Carlos - SP, Brasil
}

Recebido em 28/10/2018; aceito em 18/02/2019; publicado na web em 03/04/2019

\begin{abstract}
COLLECTIVE AUTHORSHIP IN A COMPUTER-BASED ENVIRONMENT IN UNDERGRADUATE CHEMISTRY TEACHING. Collective authorship or a text written by more than one person in a computer-based environment can bring significant benefits to chemistry teaching, mainly concerning flexibilizing forms of interaction among those involved and collaborative construction of knowledge. This work investigates collective authorship activities based on constructing argumentative texts in groups with the participation of undergraduate chemistry students. In the activity, those involved, divided into groups, followed the textual production process aiming to present a joint solution for case studies. It was possible to understand aspects of collective work in the authorship process in question regarding collaboration and cooperation based on two perspectives considered crucial for collaborative writing: conditions offered by the electronic platform called eduqui.info, and in which contexts these possibilities were present in the writing process; and the organisational aspects of the activity. Overall, groups chose to collaborate more than cooperate. In other words, data shows that most of the students worked collaboratively in groups.
\end{abstract}

Keywords: collective authorship; chemistry; eduqui.info.

\section{INTRODUÇÃO}

Em uma era marcada pelo amadurecimento cada vez mais veloz das Tecnologias da Informação e Comunicação (TIC) e pelo surgimento de novas demandas para a educação em todos os níveis, as Diretrizes Curriculares Nacionais para os Cursos de Química ${ }^{1}$ recomendam, dentre outros aspectos, a formação de profissionais preparados para disseminar informação por meio de tecnologias e o maior envolvimento dos estudantes e professores na construção do conhecimento, valorizando assim o caráter participativo, sistematizado e consciente da aprendizagem.

No documento, "'advoga-se a necessidade de criar um novo modelo de curso superior, que privilegie o papel e a importância do estudante no processo da aprendizagem, em que o papel do professor, de ensinar coisas e soluções, passe a ser ensinar o estudante a aprender coisas e soluções" (p.454), enfatizando ainda que tanto o bacharel quanto o licenciado devem "saber trabalhar em equipe [...] demonstrar bom relacionamento interpessoal e saber comunicar corretamente os projetos e resultados de pesquisa na linguagem educacional, oral e escrita" (p.459).

Percebe-se, assim, que as exigências das Diretrizes, em especial com relação à formação para a comunicação científica, rompem com o ideário de que o fomento à escrita é de responsabilidade exclusiva de professores da área de língua portuguesa na educação básica, uma verdadeira contradição, tendo em vista a importância da comunicação escrita para a Ciência e para o mundo corporativo. É válido ressaltar também que "a linguagem é essencial para clarificar, inferir, comparar, testar, observar, prever, diferenciar etc. É, também, uma forma de adquirir uma educação científica pela compreensão do mundo da Ciência e da comunicação existente nesse mesmo mundo. ${ }^{2}$ Ou seja, a aprendizagem da Ciência é vinculada à aprendizagem da linguagem da Ciência, como a escrita científica, e o seu domínio incipiente acarreta em limitações na própria concepção do que é fazer Ciência, cujas formas de comunicação possuem particularidades que destoam das situações cotidianas, com elementos, regras e estruturas próprias.

\footnotetext{
*e-mail: salete@iqsc.usp.br
}

Para além disso, em um mundo globalmente interconectado via internet, a escrita tende a assumir uma tendência mais colaborativa, com intercâmbios entre pessoas separadas por longas distâncias se tornando cada vez mais frequentes, resultando em mais e mais especialistas e estudantes colaborando para escrever relatórios, propostas, artigos e outros documentos técnicos. ${ }^{3,4}$ Por isso, o fomento da escrita no ensino de Química não deve ser encarado segundo um sentimento exclusivo de cumprimento a uma demanda legal, mas, levando em conta seu potencial para aprendizagem da Ciência e as possibilidades cada vez maiores de atuação colaborativa por meio do computador.

A utilização de computadores com o intuito de subsidiar atividades de autoria coletiva, ou escrita de um texto por mais de uma pessoa via web, mostra-se um caminho viável para atender as demandas de uma aprendizagem autônoma e colaborativa, pois o ato de escrever em grupo pode ser conduzido de maneira flexível e dinâmica, atribuindo grande valia às funções do professor e dos estudantes na aprendizagem. ${ }^{5}$ Assim, a autoria coletiva se afasta de perspectivas tradicionais de ensino centradas na figura do professor, que previamente estabelece rumos à atividade, com um desenho bem definido do produto final, mas se alinha a uma perspectiva interativa e dialógica da aprendizagem, pela qual o estudante é sujeito ativo da construção do conhecimento e compartilha com os outros a responsabilidade pela escrita. ${ }^{6}$

Além de contribuir para o aprimoramento de competências relacionadas à comunicação e escrita científica em ambiente informatizado ${ }^{7}$ e de habilidades de trabalho em grupo, essenciais para o exercício de funções na indústria e na academia, ${ }^{8,9}$ a autoria coletiva se faz uma estratégia ainda mais interessante, pois tende a aumentar a qualidade das produções textuais quando comparada às individuais, ${ }^{10,11}$ possibilita o acompanhamento e avaliação processual da atividade de autoria, ${ }^{12,13}$ e permite o aprofundamento de conteúdos de Química. ${ }^{9}$

Desse modo, sob um ponto de vista sociocultural, a autoria coletiva assume um caráter colaborativo ao enfatizar uma vertente interativa da aprendizagem, pela qual a própria aprendizagem pode ser descrita como a construção de significados compartilhados, tendo na linguagem ou na escrita uma importante ferramenta de mediação. ${ }^{14}$ Nessa modalidade de aprender, enfatiza-se também o papel da 
tecnologia como ferramenta potencializadora dessa mediação, que permite contextos mais dinâmicos, velozes e sem as restrições espaçotemporais, quando em comparação a encontros presenciais. ${ }^{6}$

No entanto, são escassas as iniciativas que prezam pela construção coletiva da informação em aulas de Ciências, a partir de wikis, blogs e rede sociais, por exemplo. ${ }^{15}$ Muitos professores de Química privilegiam tecnologias que enfatizam o papel passivo dos estudantes ao utilizarem simulações, vídeos e exercícios encontrados online, em detrimento daquelas voltadas para a construção conjunta do conhecimento. Ainda nesse sentido, iniciativas referentes à autoria coletiva em específico esbarram em resultados práticos indesejados e que a afastam do seu principal fundamento teórico-metodológico, a colaboração. ${ }^{10}$ Em alguns casos, a cultura individualista aparenta preponderar em situações nas quais os estudantes deveriam operar colaborativamente, com a participação mútua de todos, revelando que quase invariavelmente muitos não estão prontos para aceitar o conceito de construção compartilhada do conhecimento. ${ }^{16}$ É não raro em atividades de autoria coletiva os estudantes se organizarem a partir da divisão de tarefas, sem que um interfira no trabalho do outro, com casos até em que há a preferência pelo trabalho individual, nos quais apenas um integrante escreve..$^{14,17,18}$ Essas vertentes de organização impedem a concretização de objetivos de aprendizagem, em especial com relação à construção compartilhada de conhecimento e habilidades de trabalho colaborativo. ${ }^{19}$

A partir do entendimento de que o ato de escrever em grupo nem sempre se faz interativo, com participação mútua e determinante de todos os integrantes, mas também a partir da divisão do trabalho e até mesmo via o esforço de apenas um participante, emerge a necessidade de afirmar conceitos basilares que abarcam os modos como os participantes em autoria coletiva se organizam em grupo, a saber: colaboração e cooperação.

$\mathrm{Na}$ perspectiva da autoria, Martins e $\mathrm{Axt}^{20}$ reforçam o conceito de trabalho cooperativo como aquele fundamentado na divisão dos trabalhos, por meio do qual cada participante se torna responsável por uma parte da tarefa. Já o de colaboração refere-se ao engajamento mútuo dos participantes em um esforço coordenado, interativo e decisivo de todos para a realização da atividade. Os autores acrescentam que "numa mesma tarefa há momentos em que os membros de uma equipe trabalham de forma cooperativa e em um momento seguinte atuem colaborativamente", o que corroboraria com a escolha pelo termo coletivo para autoria, já que abrangeria as ideias de colaboração e cooperação. Para a autoria, é possível ainda estabelecer tendências de colaboração e cooperação, ou seja, uma atividade de escrita em grupo pode convergir ao engajamento múltiplo, por um lado, ou a divisão do trabalho, por outro. ${ }^{14}$

Já para Dillenbourg, ${ }^{19}$ atividades de caráter colaborativo podem ser definidas, ainda que de forma superficial, como uma situação em que duas ou mais pessoas aprendem ou tentam aprender algo juntas. $\mathrm{O}$ autor acrescenta que a principal diferença entre colaboração e cooperação se encontra no modo como os grupos se organizam para realização da tarefa: na colaboração, todos trabalham em conjunto, em um esforço coordenado, a fim de alcançar o objetivo a que se propuseram. Já na cooperação, a estrutura hierárquica prevalece, e cada um dos membros da equipe é responsável por uma parte da tarefa. Com base nessa concepção, Figueiredo ${ }^{21}$ aponta as principais diferenças e semelhanças entre a aprendizagem colaborativa e a cooperativa (Quadro 1).

No contexto da autoria coletiva, há também uma variedade de concepções a respeito da colaboração e cooperação. Em primeiro lugar, o termo autoria coletiva em inglês é usualmente referido como collaborative writting ou, em tradução livre, escrita colaborativa. No Brasil, vários pesquisadores adotam o conceito de autoria coletiva como o processo de construção de texto por mais de uma pessoa em
Quadro 1. Semelhanças e diferenças entre a aprendizagem colaborativa e a cooperativa, adaptado da ref. 21.

\begin{tabular}{|c|c|}
\hline Aprendizagem colaborativa & Aprendizagem cooperativa \\
\hline \multicolumn{2}{|c|}{ Diferenças } \\
\hline O foco é no processo & O foco é no produto \\
\hline $\begin{array}{c}\text { As atividades dos membros } \\
\text { do grupo são geralmente não } \\
\text { estruturadas: os seus papeis são } \\
\text { definidos ao passo que a atividade } \\
\text { se desenvolve }\end{array}$ & $\begin{array}{c}\text { As atividades dos membros do } \\
\text { grupo são geralmente estruturadas: } \\
\text { os seus papeis são definidos } \\
\text { a priori, sendo resguardada a } \\
\text { possibilidade de renegociação } \\
\text { desses papeis }\end{array}$ \\
$\begin{array}{c}\text { Com relação ao gerenciamento das } \\
\text { atividades, a abordagem é centrada } \\
\text { no aluno }\end{array}$ & $\begin{array}{c}\text { Com relação ao gerenciamento das } \\
\text { atividades, a abordagem é centrada } \\
\text { no professor }\end{array}$ \\
\hline $\begin{array}{c}\text { O professor não dá instruções } \\
\text { aos alunos sobre como realizar as } \\
\text { atividades em grupo }\end{array}$ & $\begin{array}{c}\text { O professor dá as instruções aos } \\
\text { alunos sobre como realizar as } \\
\text { atividades em grupo }\end{array}$ \\
\hline \multicolumn{2}{|c|}{ Semelhanças } \\
\hline $\begin{array}{c}\text { Os alunos tornam-se mais ativos no processo de ensino-aprendizagem, já } \\
\text { que não recebem passivamente as informações do professor }\end{array}$ \\
\hline $\begin{array}{c}\text { O ensino e aprendizagem tornam-se experiências compartilhadas entre } \\
\text { os alunos e o professor }\end{array}$ \\
\hline A participação em pequenos grupos favorece o desenvolvimento das \\
habilidades intelectuais e sociais
\end{tabular}

ambiente informatizado, ${ }^{22}$ enquanto outros preferem o termo autoria colaborativa $^{23}$ e até mesmo autoria cooperativa. ${ }^{24} \mathrm{~A}$ variedade de conceitos reflete a multiplicidade de sentidos que pode ser atribuída à colaboração e à cooperação, ou mesmo à intencionalidade do professor no que se refere à forma de organização dos envolvidos e do suporte eletrônico para autoria.

A partir disso, levando em conta as potencialidades da autoria coletiva para a aprendizagem em Química e as tendências, tanto de colaboração quanto de cooperação que regem o processo de escrita, o presente artigo tem como objetivo investigar uma atividade de autoria coletiva organizada com estudantes de graduação em Química, unidos na construção de textos argumentativos a partir de temas sociocientíficos. O foco da investigação volta-se para a identificação das estratégias de autoria, ou os modos como os estudantes se organizam para a escrita em grupo, e das funções por eles desempenhadas, entendidas como responsabilidades de cada integrante no processo de escrita, sendo as seguintes as questões de pesquisa: Quais estratégias organizacionais emergiram durante o processo de escrita? Quais funções foram exercidas pelos estudantes durante o processo de autoria?

Nesse contexto, buscamos trazer contribuições no que tange ao favorecimento de reflexões sobre a elaboração e implementação de práticas de autoria coletiva em ambiente informatizado no ensino de Química, assim como para amenizar a lacuna existente no que diz respeito a referenciais que abordem as referidas práticas, em especial em cursos de graduação.

\section{CONTEXTO DE APLICAÇÃO DA ATIVIDADE DE AUTORIA COLETIVA}

As atividades de autoria foram desenvolvidas com 36 estudantes de graduação em Química do Instituto de Química de São Carlos da Universidade de São Paulo matriculados na disciplina Comunicação e Expressão em Linguagem Científica II (teórica, 3 créditos), de caráter semestral e obrigatório. A proposta da disciplina é aprimorar a capacidade de escrita, leitura e comunicação oral dos estudantes 
no que se refere aos aspectos gerais da linguagem científica, o que respalda o desenvolvimento de atividades de escrita em grupo.

Para a mediação do processo de escrita, foi utilizado um Ambiente Virtual de Aprendizagem (AVA) de nome eduqui.info, cuja proposta é alocar atividades colaborativas online, inclusive de autoria coletiva. ${ }^{25}$ As atividades no eduqui.info tiveram a duração de 60 dias.

Inicialmente, os alunos foram divididos em grupos de 8 a 10 integrantes (Tabela 1) e convidados a ler e solucionar individualmente os estudos de caso $^{26,27}$ denominados IP, CA, DG e SA, disponibilizados no AVA e descritos sucintamente a seguir. A solução encontrada foi postada no eduqui.info na forma de um texto argumentativo com mínimo de 750 palavras.

Tabela 1. Distribuição dos estudantes segundo os estudos de caso

\begin{tabular}{lcccc}
\hline & Grupo 1 & Grupo 2 & Grupo 3 & Grupo 4 \\
\hline Estudos de caso & IP & CA & DG & SA \\
\hline Número de integrantes & 9 & 10 & 10 & 8 \\
\hline
\end{tabular}

Os títulos dos estudos de caso e a problemática neles envolvida são: Idade do plástico (IP): os estudantes devem propor alternativas ao uso de embalagens de poli(tereftalato de etileno) - PET e argumentar a favor de uma delas; Cana-de-açúcar pelos ares (CA): os estudantes devem indicar combustíveis à base de cana-de-açúcar para substituir a gasolina de aviação no abastecimento de uma frota de aviões e argumentar a favor de um deles; De galão em galão, a prainha vai para o ralo $(D G)$ : os estudantes são colocados no papel de profissionais contratados para desenvolver um plano de mitigação, em caso de possíveis vazamentos de petróleo em uma região, devendo propor soluções para o problema e argumentar a favor de uma delas; Socorro, eu não quero alface! (SA): os estudantes devem indicar possibilidades para substituir a gordura trans em biscoitos e argumentar a favor de uma delas.

De posse das soluções individuais oferecidas pelos alunos para os casos, o docente responsável pela disciplina dividiu os estudantes em 17 duplas e um trio, conforme a Tabela 2. Os grupos eram compostos por alunos que indicaram soluções distintas para um mesmo caso.

Tabela 2. Distribuição dos estudantes em grupos para cada estudos de caso

\begin{tabular}{lcccc}
\hline Estudo de Caso & IP & CA & DG & SA \\
\hline Agrupamentos & $\begin{array}{c}1 \text { trio e 3 } \\
\text { duplas }\end{array}$ & 5 duplas & 5 duplas & 4 duplas \\
\hline
\end{tabular}

Em seguida, os grupos foram alocados em fóruns do AVA (espaço para discussão assíncrona) para que seus integrantes debatessem sobre as distintas soluções, devendo alcançar ao fim uma solução comum. Após as interações no fórum, os estudantes foram dispostos nos chats do AVA com o intuito de, em grupo, redigir um texto de no mínimo 500 palavras com a solução acordada anteriormente.

O foco de investigação deste trabalho volta-se às interações realizadas nos chats, desconsiderado a formação em trio já que, pela organização única, apresenta configurações de interação distintas das composições em duplas. Além disso, dois chats, um do caso CA e outro do caso DG, não tiveram suas atividades concluídas e assim também não fazem parte do escopo de análise deste trabalho. Assim, a investigação se deu em quinze chats: três para o caso IP; quatro para o caso CA; quatro para o caso DG; e quatro para o caso SA, contando assim com 30 participantes.

Para melhor ilustrar a autoria coletiva no eduqui.info, o esquema da Figura 1 toma como base as ações de dois estudantes do caso IP e mostra as etapas de autoria que vivenciaram. Na Figura 1 e no decorrer do texto as duplas são identificadas pelo caso que lhe foi atribuído (IP, por exemplo) e o grupo que compuseram (1 a 3 , para este caso). Já para a identificação de um certo estudante, será acrescido a letra A ou B. Assim, o estudante IP2.A se refere ao estudante A, da dupla 2.

A Figura 1 indica que na etapa de autoria individual (I) dois alunos resolveram o caso IP e apontaram soluções distintas para ele: a reciclagem das embalagens PET e a substituição das embalagens de PET por embalagens biodegradáveis. Ciente da diferença entre as respostas, o professor os uniu na dupla denominada IP2, para que interagissem no fórum do eduqui.info (II), onde produziram a solução conjunta para o caso: substituição do PET por plásticos biodegradáveis. Na sequência, ocorreu a autoria coletiva, quando os mesmos redigiram no chat um texto sobre a solução acordada no fórum.

Durante todo o processo o professor teve lugar central: no estágio inicial, seu papel foi de organizador; já na etapa de discussão, agiu não apenas como um moderador, mas também como um facilitador para criação de um ambiente propício à promoção de discussões assíncronas. Nessa perspectiva, os estudantes foram orientados sobre a redação do texto coletivo, conforme trecho extraído do AVA: "Este (o texto) deve apresentar a melhor solução para o caso encontrado pela dupla e deve ter caráter argumentativo. Ou seja, apresentem o problema/dado existente no caso e argumentem a favor da solução encontrada no fórum (...)".

No início da atividade, foi também recomendado que os alunos não debatessem sobre a construção do texto pessoalmente ou pela internet, por meio de outras ferramentas, como rede sociais e e-mails, privilegiando o eduqui.info. Uma vez estabelecidas as interações para o processo de autoria coletiva, o professor intervinha quando os estudantes não atendiam aos requisitos da atividade, no sentido de corrigir encaminhamentos não desejados, distantes dos objetivos traçados e das orientações da literatura. Por fim, cabia a ele encerrar as interações no chat com uma última mensagem quando da submissão do texto coletivo.
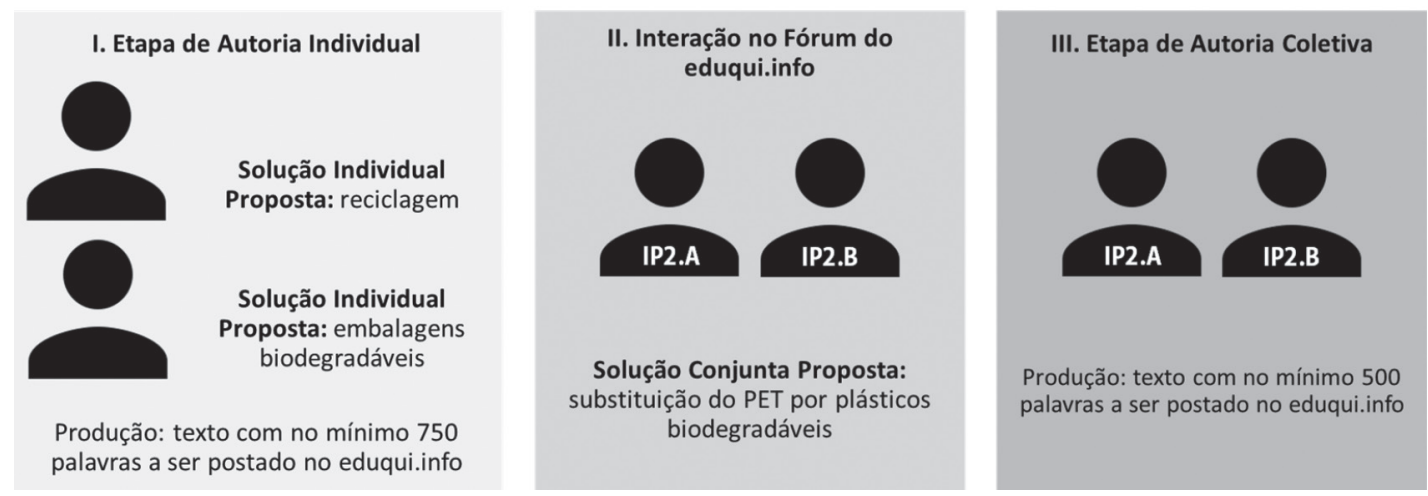

Figura 1. Etapas de autoria vivenciadas pelos alunos, tomando como exemplo o caso IP 
Cabe destacar que as estratégias de autoria e os modos como se organizaram para a escrita em grupo não foram direcionados por ações do professor, se deram, portanto, de forma espontânea, a critério dos próprios estudantes.

\section{REFERENCIAIS TEÓRICO-METODOLÓGICOS E PROCEDIMENTOS DE ANÁLISE}

Para a identificação das estratégias e funções exercidas pelos participantes durante o processo de autoria coletiva, referenciais com taxonomia e definição próprias foram utilizados, conforme descrições a seguir.

Em primeiro lugar, para Lowry, Curtis e Lowry, ${ }^{28}$ estratégias para autoria coletiva referem-se a "modos de organização definidos pelos participantes para coordenar a redação do texto em grupo". Para os autores, as diferentes estratégias assumidas pelos participantes variam com o grau de engajamento dos mesmos durantes as fases de planejamento e escrita. Neste artigo, é adotada uma taxonomia adaptada da proposta de Lowry, Curtis e Lowry, ${ }^{28}$ a qual é coerente também à tipificação presente nos trabalhos de Onrubia e Engel ${ }^{14}$ e Saunders ${ }^{29} \mathrm{e}$ abrangem quatro possíveis estratégias para a autoria coletiva:

Construção individual: a atividade de escrita é delegada a apenas um integrante após todos os participantes concordarem sobre a estrutura e conteúdo do texto;

Construção paralela - divisão horizontal: cada estudante se torna responsável por um determinado trecho ou parágrafos que constituirão o texto coletivo. O texto final será formado por meio da compilação, sem modificações ou avaliações, dos trechos propostos;

Construção paralela - divisão estratificada: os participantes se especializam em funções distintas, por meio das quais, por exemplo, um estudante redige um texto parcialmente completo e outro se encarrega de revisar e editar a produção;

Construção integrada: a redação do documento é baseada em discussões síncronas, nas quais todos os participantes contribuem igualmente para o texto, avaliando e modificando suas contribuições e a do colega.

Essas quatros modalidades de estratégia para a construção do texto coletivo implicam em diferentes combinações no que diz respeito à responsabilidade pelo gerenciamento da atividade e à redação do texto. ${ }^{14} \mathrm{Na}$ autoria individual, o gerenciamento e a redação do texto é responsabilidade exclusiva de um dos integrantes. $\mathrm{Na}$ construção paralela - divisão horizontal, a responsabilidade pelo controle da atividade e a redação são independentes, no sentido de que cada participante trabalha paralelamente ao parceiro e apenas gerencia e redige aquilo que lhe foi reservado. Já na construção paralela - divisão estratificada, os participantes assumem o controle e a redação do texto de forma separada e em tempos distintos. Por último, na construção integrada o gerenciamento da atividade e a redação são compartilhados igualmente entre os membros do grupo.

Investigações que tratam das estratégias para autoria coletiva costumam associar tendências colaborativas e cooperativas a cada uma delas. ${ }^{14,28} \mathrm{~A}$ partir da tipologia e reflexões presentes nesses manuscritos, é constatado que as três primeiras estratégias baseiamse na divisão de trabalho, quando o controle da atividade e a redação do texto recaem separadamente, individualmente, de forma paralela ou em tempos distintos, operando assim de forma cooperativa. Em contrapartida, na construção integrada, os estudantes controlam e redigem o texto de forma dinâmica e sem restrições, organizando-se, assim, colaborativamente.

No que se refere às funções em autoria coletiva, estas aludem à "responsabilidade assumida formal ou informalmente por um participante no decorrer do processo de escrita". ${ }^{28} \mathrm{O}$ participante, segundo os autores, pode ainda assumir múltiplas funções ou mudar de responsabilidade no decorrer da atividade. A taxonomia utilizada neste trabalho para estabelecer a(s) função(ões) cumpridas por cada participante é baseada conjuntamente nas propostas de Saunders ${ }^{29} \mathrm{e}$ de Lowris, Curtis e Lowris, ${ }^{28}$ as quais têm em comum as seguintes funções e definições:

Planejamento: consiste em decidir sobre um público, propósito e tópico, gerar e selecionar ideias e desenvolver um esquema organizacional implícito ou explícito para a escrita coletiva;

Escrita: envolve a responsabilidade de escrever parte ou a totalidade do conteúdo em um documento de autoria coletiva;

Revisão: envolve a leitura do texto completo ou trecho do mesmo com a identificação de áreas que precisam ser melhoradas, sugestão de encaminhamentos futuros ou reforço da pertinência do que foi posto, mas sem efetuar correções.

Edição: inclui a edição de trechos ou do rascunho final do texto, realizando alterações quanto ao conteúdo do texto coletivo.

A relevância dessa perspectiva de análise reside no fato de que tanto as estratégias assumidas pelos estudantes para a autoria coletiva quanto os papéis exercidos por cada um durante o processo de escrita são reveladores, como será discutido na seção seguinte, da natureza do trabalho coletivo, no que se refere ao grau de colaboração ou cooperação presente na atividade, e aprendizagem de elementos que emergem do processo de autoria coletiva.

Como fontes de dados para a identificação das estratégias e funções, lançou-se mão das mensagens trocadas pelos estudantes no processo de criação textual coletiva no chat do eduqui.info (Etapa II da Figura 1). Relatórios dessas interações são gerados pelo próprio AVA por meio de uma função denominada de "histórico". Os mesmos conjuntos de dados foram então categorizados duplamente: uma em função das estratégias e outra segundo as funções para autoria coletiva. Para as estratégias de escrita, cada chat foi categorizado em apenas uma categoria. Quanto às funções, cada participante foi enquadrado em pelo menos uma delas.

A título de exemplo do processo de autoria coletiva no eduqui. info e da maneira com que se procedeu a análise, são ilustrados, a seguir, trechos da discussão da dupla IP2, bem como sua classificação no que diz respeito às estratégias para a autoria coletiva empregadas e funções desempenhadas por cada estudante.

Para facilitar o entendimento das discussões sobre o processo de autoria coletiva, este foi dividido em três, a saber: etapa introdutória (momento inicial quando os estudantes planejam o processo de autoria coletiva); etapa de construção do texto (momento no qual os participantes contribuem com fragmentos textuais para o texto coletivo, negociam as contribuições e em alguns casos também os modificam); e submissão do texto (etapa final quando os estudantes submetem o texto coletivo e concluem as interações no chat).

\section{Etapa introdutória}

No chat da dupla IP2, as interações no ambiente iniciam a partir de mensagens pelas quais os estudantes planejam o processo de escrita do texto. Nessa etapa, nas primeiras mensagens no chat, os participantes negociam o processo de autoria coletiva. O Quadro 2 mostra a primeira mensagem produzida pelos membros da dupla.

A mensagem em destaque no Quadro 2 não é a única da etapa introdutória. Outras são submetidas ao chat nessa fase e

Quadro 2. Mensagem de IP2.A na etapa introdutória para a dupla IP2

Estudante IP2.A

Acho que para introdução devemos colocar dados relacionados à canade-açúcar, tipo... a produção mundial, a produção no Brasil, se o bagaço já era reaproveitado para outras coisas, falar um pouco da importância do biodegradável... o que acha? 
tratam do planejamento do processo de escrita. No chat da dupla IP2, o estudante IP2.A inicia as interações propondo que fossem abordados na introdução aspectos gerais sobre a cana-de-açúcar, matéria-prima para a solução alcançada em conjunto. Já o estudante IP2.B, em resposta ao colega IP2.A, concorda com a estratégia e sugere o que deveria ser apresentado nas demais seções do texto (Quadro 3).

Quadro 3. Mensagem de IP2.B na etapa introdutória para a dupla IP2

\section{Estudante IP2.B}

Acho que ficaria ótimo. Podemos expor também as ideias da reciclagem e depois discutimos os contras da reciclagem, e depois começamos a falar as coisas boas do biodegradável.

No chat da dupla IP2, etapa introdutória, os estudantes se dedicam exclusivamente ao planejamento e negociação da atividade.

\section{Etapa de construção do texto}

A etapa de construção do texto é iniciada a partir da submissão de fragmentos textuais para a produção coletiva. O trecho em destaque no Quadro 4 ilustra fragmento de uma das primeiras mensagens da dupla para compor o texto coletivo.

Quadro 4. Mensagem de IP2.B na etapa de construção do texto

\section{ESTUDANTE IP2.B}

[...] O Brasil é um dos maiores produtores mundiais de cana-de-açúcar e em muitas partes do país o bagaço produzido é descartado de forma inadequada. Este tem utilidade na adubação do solo e principalmente na sintetização do plástico biodegradável.

Após inserir o fragmento em destaque no Quadro 4, o estudante IP2.B esclarece o próposito da mensagem, sugerindo uma estratégia para submeter novas contribuições. A mensagem encontra-se em destaque no Quadro 5.

Quadro 5. Segunda mensagem de IP2.B na etapa de construção do texto

\section{ESTUDANTE IP2.B}

A parte que está entre aspas não foi copiada de nenhum lugar, eu redigi, acho que dá pra irmos colocando assim entre aspas pra quando formos montar o texto não precisarmos redigir tudo de novo, é só copiar e colar.

A partir, então, das contribuições inseridas para a formação do texto coletivo e a negociação da pertinência dessas contribuições, os participantes da dupla engajam-se na lapidação do texto coletivo em formação. O Quadro 6 mostra este movimento em mensagens da dupla, quando o estudantes IP2.A modifica a proposta de trecho inserida pelo seu colega e que está em destaque no Quadro 4.

Logo em seguida, os estudantes inserem mensagens a partir das

Quadro 6. Mensagens de IP2.A na etapa de construção do texto

ESTUDANTE IP2.A Trechos adicionados [...] O Brasil é hoje o maior produtor mundial de cana-de-açúcar. A modernização das 430 usinas em operação no país, com a adoção de novas tecnologias desde o plantio até a produção de açúcar, etanol e bioeletricidade, fortaleceram o setor, reconhecido mundialmente por seu pioneirismo e sua eficiência produtiva. Em nuitas partes do país o bagaço produzido é descartado de forma inadequada. Este tem utilidade na adubação do solo e principalmente da síntese do plástico biodegradável. Ainda como ponto positivo, quanto a uma/possível produção de biodegradáveis, pesquisas apontam que na próxima década a área de cultivo da cana-de-açúcar aumentará em $\mathbf{5 0 \%}$, resultando em uma área total de 10 milhões de hectares no Brasil. quais pretendem justificar, sintetizar ou solicitar a avaliação do colega com relação à ação emprendida por si próprio ou pelo parceiro. $\mathrm{O}$ Quadro 7 mostra exemplo desses movimentos.

Quadro 7. Terceira mensagem de IP2.B na etapa de construção do texto

\section{ESTUDANTE IP2.B}

Tá bom??

\section{Etapa de submissão do texto}

A última etapa do processamento textual inicia a partir da inserção do texto coletivo como única mensagem ao chat. Para a dupla IP2, após alterações e negociação dos fragmentos textuais, o estudante IP2.B compila todas as contribuições, revisa o texto e ainda faz algumas modificações. O Quadro 8 mostra um fragmento do texto coletivo da dupla.

Quadro 8. Trecho do texto coletivo da dupla IP2

\begin{tabular}{|l|}
\hline ESTUDANTE IP2.B \\
Fabricação de biodegradável através do bagaço da cana. O problema da \\
poluição é muito discutido atualmente, muitos métodos são propostos e \\
estudados para diminuir a agressão de materiais poluentes no ecossistema. \\
Um deles é a substituição das garrafas plásticas por PETs biodegradáveis, \\
que são produzidos através de sínteses bacterianas. A espécie Alcaligenes \\
eutrophus produz através da cana-de-açúcar um polímero da família \\
polihidroxialcanoatos (PHA), que é um dos resultados do metabolismo \\
natural de várias espécies de bactérias [...].
\end{tabular}

O chat para a dupla IP2 foi finalizado com o estudante IP2.A avaliando o trabalho coletivo para a construção do texto. O Quadro 9 mostra essa última mensagem.

Quadro 9. Última mensagem de IP2.A na etapa de submissão do texto

ESTUDANTE IP2.A

Bom...acho q missão concluída...parabéns pra nós, foi muito bom trabalhar com vc, estudante IP2.B, até a próxima XD.

Tendo em vista as mensagens expostas nos Quadros 2 a 9, é possível categorizar a estratégia para autoria coletiva da dupla IP2, como sendo do tipo construção integrada. De fato, foi verificada a existência privilegiada de discussões síncronas, nas quais IP2.A e IP2.B colaboram igualmente para o texto, avaliando e modificando suas contribuições e as do parceiro. No que se refere às funções desempenhadas pelos dois estudantes do caso IP2, foi constatado por meio das mensagens as seguintes para os seus dois componentes: planejamento, escrita, revisão e edição.

O mesmo procedimento de análise realizado para a dupla IP foi levado a cabo para as demais e os resultados alcançados estão apresentados no tópico a seguir.

\section{RESULTADOS E DISCUSSÃO}

Nesta seção, para cada caso, serão apresentadas as estratégias e funções exercidas por cada dupla, e, em seguida, considerações serão tecidas a respeito do panorama presente para cada conjunto de duplas, levando em consideração as tendências de cooperação e colaboração.

\section{Estudo de caso IP}

Para o estudo de caso IP, três duplas se engajaram na redação coletiva de soluções para o problema dos estudantes de Química, 
preocupados com as embalagens PET. As soluções propostas foram as seguintes: a dupla IP1 indicou a reciclagem; a dupla IP2 indicou substituição do PET por plásticos biodegradáveis; a dupla IP3 indicou uma combinação das soluções anteriores. Em cada dupla, identificou-se uma estratégia para autoria coletiva e seus integrantes desempenharam no mínimo três funções, como mostra o Quadro 10.

O Quadro 10 mostra que, entre as três duplas do caso, as duplas IP1 e IP2 assumiram a estratégia de construção integrada e a dupla IP3 lançou mão da estratégia de construção paralela - divisão estratificada. Como já relatado, a primeira privilegia discussões síncronas, nas quais todos os participantes colaboram igualmente para o texto, avaliando e modificando suas contribuições e as do parceiro. Já a estratégia de construção paralela - divisão estratificada é levada a cabo quando os participantes se especializam em funções distintas, por meio das quais, por exemplo, um estudante redige um texto parcialmente completo e outro se encarrega de empreender revisões e edições, sem mais a contrapartida do parceiro. Em outras palavras, um inicia o texto e o outro finaliza.

Com relação às funções, o Quadro 10 também destaca que houve quatro tipos de combinações de funções para cada um dos seis participantes: planejamento, escrita, revisão e edição; planejamento, escrita e revisão; planejamento, escrita e edição; e planejamento e escrita. Para aqueles casos com estratégia de construção integrada, pelo menos um integrante exerceu as quatro funções. Já para a dupla IP3, não foi constado o exercício da função revisão por nenhum dos membros: IP3.B deu início ao processo, sugerindo uma estrutura para o texto e apresentando suas contribuições quanto ao conteúdo; em seguida, a condução ficou a encargo unicamente de IP3.A, que também sugeriu uma estrutura para o texto, inseriu contribuições e o modificou.

A distribuição das funções, junto com a caracterização da estratégia adotada, fornece indícios de como o texto foi construído.

\section{Estudo de caso CA}

Para o estudo de caso CA, quatro duplas se engajaram na redação coletiva de soluções para o problema do abastecimento de aviões por combustíveis produzidos a partir da cana-de-açúcar. As soluções indicadas foram as seguintes: a dupla CA1 propôs substituição da gasolina de aviação no abastecimento das aeronaves por uma mistura de bioquerosene e querosene; a dupla CA2 propôs substituição da gasolina de aviação no abastecimento das aeronaves pelo diesel proveniente da cana-de-açúcar; a dupla CA3 propôs substituição da gasolina de aviação no abastecimento das aeronaves pelo etanol; a dupla CA4 propôs substituição da gasolina de aviação no abastecimento das aeronaves pelo etanol para as aeronaves de pequeno porte e o diesel de cana-de-açúcar para as de grande porte. Em cada dupla, identificou-se uma estratégia para autoria coletiva e seus integrantes desempenharam de uma até as quatro funções, como mostra o Quadro 11.

O Quadro 11 mostra que três duplas do caso CA (CA1, CA2 e CA4) adotaram a estratégia de construção integrada, um número significativo, assim como entre as duplas do caso IP. Apenas uma dupla fugiu dessa tendência, constatação também para as duplas do caso IP, lançando mão da estratégia de construção individual. Essa estratégia toma forma quando a escrita é delegada a apenas um integrante, após os participantes concordarem sobre a estrutura e o conteúdo do texto.

O Quadro 11 também revela quatro tipos de combinações de funções para cada um dos oito estudantes do caso CA, a saber: planejamento, escrita, revisão e edição; planejamento, escrita e edição; planejamento e escrita; e planejamento. Para as duplas que adotaram a estratégia de construção integrada, pelo menos um participante desempenhou as quatros funções. Já para a dupla CA3, que adotou a estratégia de construção individual, duas funções foram exercidas: CA3.A e CA3.B planejaram como se daria a escrita, ficando a encargo apenas de CA3.B a redação do texto. Ou seja, o estudante CA3.A desempenhou as funções de planejamento e escrita, enquanto CA3.B, somente a de planejamento.

\section{Estudo de caso DG}

Já para o estudo de caso DG, outras quatro duplas se engajaram na redação coletiva de soluções para o problema da eminência de

Quadro 10. Estratégias e funções para os integrantes do caso IP

\begin{tabular}{|c|c|c|c|}
\hline \multirow{2}{*}{ Dupla } & Integrante & Estratégia & Função \\
\hline \multirow{2}{*}{ IP1 } & IP1.A & \multirow{2}{*}{ Construção integrada } & Planejamento, escrita e revisão \\
\cline { 2 - 2 } & IP1.B & & Planejamento, escrita, revisão e edição \\
\cline { 2 - 2 } IP2 & IP2.A & \multirow{2}{*}{ Construção integrada } & Planejamento, escrita, revisão e edição \\
\cline { 2 - 2 } & IP2.B & \multirow{2}{*}{ Construção paralela - divisão estratificada } & Planejamento, escrita, revisão e edição \\
\cline { 2 - 2 } & IP3.A & & Planejamento e escrita \\
\cline { 2 - 2 } & IP3.B & & Planejamento, escrita e edição \\
\hline
\end{tabular}

Quadro 11. Estratégias e funções para os integrantes do caso CA

\begin{tabular}{|c|c|c|c|}
\hline Dupla & Integrante & Estratégia & Função \\
\hline \multirow{2}{*}{ CA1 } & CA1.A & \multirow{2}{*}{ Construção integrada } & Planejamento, escrita e edição \\
\hline & CA1.B & & Planejamento, escrita, revisão e edição \\
\hline \multirow{2}{*}{ CA2 } & CA2.A & \multirow{2}{*}{ Construção integrada } & Planejamento, escrita, revisão e edição \\
\hline & CA2.B & & Planejamento, escrita, revisão e edição \\
\hline \multirow{2}{*}{ CA3 } & CA3.A & \multirow{2}{*}{ Construção individual } & Planejamento e escrita \\
\hline & CA3.B & & Planejamento \\
\hline \multirow{2}{*}{ CA4 } & CA4.A & \multirow{2}{*}{ Construção integrada } & Planejamento, escrita, revisão e edição \\
\hline & CA4.B & & Planejamento, escrita, revisão e edição \\
\hline
\end{tabular}


vazamento de petróleo na cidade de Macaé. As soluções propostas para o caso foram: as duplas DG1, DG2 e DG4 indicaram utilização de materiais adsorventes e técnicas de bioremediação; a dupla DG3 indicou utilização de barreiras de contenção e técnicas de retirada do petróleo por magnetismo. Para cada dupla, identificou-se uma estratégia de autoria coletiva, com seus integrantes exercendo um ou até as quatro funções, como mostra o Quadro 12.

O Quadro 12 mostra que três duplas do caso DG (DG1, DG2 e DG4) adotaram a estratégia de construção integrada, mesma quantidade dos agrupamentos do caso CA. E seguindo a tendência do caso IP e CA, apenas uma dupla lançou mão de uma estratégia diferente: dupla DG3 adotou a construção paralela - divisão horizontal. Essa estratégia se dá quando os participantes trabalham simultaneamente e cada um se torna responsável por um determinado trecho ou parágrafos que constituirão o texto coletivo, sendo o texto final formado por meio da compilação, sem modificações ou avaliações, dos trechos propostos.

Quanto às funções, o Quadro 12 revela três tipos de combinações de funções para cada um dos oito estudantes do caso DG, que foram: planejamento, escrita, revisão e edição; planejamento, escrita e revisão; e escrita. Para as duplas que adotaram a estratégia de construção integrada, pelo menos um integrante desempenhou as quatro funções, com apenas uma ocorrência no qual o integrante (DG1.A) desempenhou três funções, a saber: planejamento, escrita e revisão. Quanto à dupla DG3, que lançou mão da estratégia de construção paralela-divisão horizontal, seus integrantes exerceram apenas a função de escrita: DG3.B deu início ao processo, apresentando suas contribuições quanto ao conteúdo e o mesmo procedimento foi adotado por DG3.A. Na sequência, DG3.B fez a associação direta das duas contribuições e finalizou a produção textual. A função de cada um deles é, portanto, condizente com a própria estratégia, pois por meio desta os integrantes redigiram sua contribuição e o texto final foi composto, sem edição e revisão, pela justaposição das partes.

\section{Estudo de caso SA}

Por fim, no estudo de caso SA, quatro duplas se encarregaram de redigir coletivamente soluções para o problema da Dona Socorro e as gorduras trans. As soluções indicadas para o caso foram: a dupla SA1 propôs, a curto prazo, utilização de ingredientes sem gorduras trans e, a longo prazo, utilização do óleo de palma como uma das matérias-primas; a dupla SA2 propôs utilização de ingredientes sem gorduras trans; e as duplas SA3 e SA4 propuseram utilização do óleo de palma como uma das matérias-primas. Para cada dupla, identificouse uma estratégia de autoria coletiva e duas ou mais funções, como mostra o Quadro 13.

O Quadro 13 mostra que três duplas do caso SA (SA1, SA3 e SA4) adotaram a estratégia de construção integrada, distribuição semelhante às das duplas dos casos CA e DG. E seguindo a tendência de todos os casos, apenas um grupo lançou mão de uma estratégia distinta: dupla SA2, que lançou mão da construção paralela-divisão estratificada, presente também na dupla IP3.

No que se refere às funções, o Quadro 13 revela que ocorreram dois tipos de combinações de funções para os oitos estudantes do caso SA: planejamento, escrita, revisão e edição; e planejamento e escrita. Para os integrantes das duplas do caso que adotaram a estratégia integrada houve o exercício, mais uma vez, das quatro funções, agora por todos os integrantes que lançaram mão da estratégia. Quanto à dupla SA2, que se organizou por meio da estratégia construção paralela - divisão estratificada, o participante SA2.A exerceu a função de planejamento e escrita, enquanto o parceiro, integrante SA2.B, desempenhou as quatro funções. Apesar de um participante desempenhar todas as funções, a dupla SA2 se diferencia das demais pelo modo como as mesmas foram exercidas, evidente na estratégia de escrita, por meio do qual os integrantes, apesar de planejarem a atividade juntos, trabalham em tempos separados durante a redação: estudante SA2.A propõe um trecho e em seguida finaliza sua participação; estudante SA2.A revisa a contribuição do parceiro, a edita e escreve novos trechos.

Quadro 12. Estratégias e funções para os integrantes do caso DG

\begin{tabular}{|c|c|c|c|}
\hline Dupla & Integrante & Estratégia & Função \\
\hline \multirow{2}{*}{ DG1 } & DG1.A & \multirow{2}{*}{ Construção integrada } & Planejamento, escrita e revisão \\
\hline & DG1.B & & Planejamento, escrita, revisão e edição \\
\hline \multirow{2}{*}{ DG2 } & DG2.A & \multirow{2}{*}{ Construção integrada } & Planejamento, escrita, revisão e edição \\
\hline & DG2.B & & Planejamento, escrita, revisão e edição \\
\hline \multirow{2}{*}{ DG3 } & DG3.A & \multirow{2}{*}{ Construção paralela - divisão horizontal } & Escrita \\
\hline & DG3.B & & Escrita \\
\hline \multirow{2}{*}{ DG4 } & DG4.A & \multirow{2}{*}{ Construção integrada } & Planejamento, escrita e revisão \\
\hline & DG4.B & & Planejamento, escrita, revisão e edição \\
\hline
\end{tabular}

Quadro 13. Estratégias e funções para os integrantes do caso SA

\begin{tabular}{|c|c|c|c|}
\hline Dupla & Integrante & Estratégia & Função \\
\hline \multirow{2}{*}{ SA1 } & SA1.A & \multirow{2}{*}{ Construção integrada } & Planejamento, escrita, revisão e edição \\
\hline & SA1.B & & Planejamento, escrita, revisão e edição \\
\hline \multirow{2}{*}{ SA2 } & SA2.A & \multirow{2}{*}{ Construção paralela - divisão estratificada } & Planejamento e escrita \\
\hline & SA2.B & & Planejamento, escrita, revisão e edição \\
\hline \multirow{2}{*}{ SA3 } & SA3.A & \multirow{2}{*}{ Construção integrada } & Planejamento, escrita, revisão e edição \\
\hline & SA3.B & & Planejamento, escrita, revisão e edição \\
\hline \multirow{2}{*}{ SA4 } & SA4.A & \multirow{2}{*}{ Construção integrada } & Planejamento, escrita, revisão e edição \\
\hline & SA4.B & & Planejamento, escrita, revisão e edição \\
\hline
\end{tabular}


A análise das estratégias assumidas pelos estudantes permitiu constatar que a construção integrada prevaleceu em todos os grupos de chats investigados, a saber: dois para o caso IP; três para o caso CA; três para o caso DG; e três para o caso SA. Por outro lado, exatamente um chat para cada grupo teve seus integrantes lançando mão de uma estratégia diferente da integrada, a saber: construção paralela - divisão estratificada (duplas IP3 e SA2); construção individual (dupla CA3), construção paralela - divisão horizontal (dupla DG3). Dessa forma, a Figura 2 sintetiza e ilustra a distribuição quantitativa das estratégias assumidas por cada dupla.

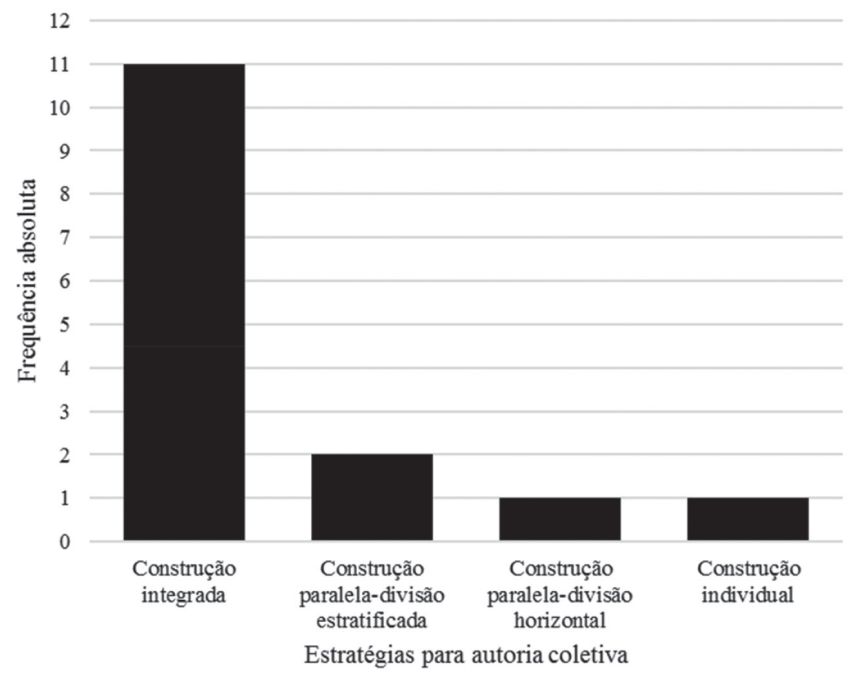

Figura 2. Distribuição quantitativa dos tipos de estratégias

Segundo Onrubia e Engel, ${ }^{14}$ a construção integrada, identificada em onze entre os quinze chats, tende a um caráter mais colaborativo do processo de criação textual, já que há discussões sincronizadas e a contribuição decisiva de todos os participantes nas diversas etapas de criação textual. Além disso, as demais estratégias, distribuídas em quatro dos quinze chats, apresentam um caráter mais cooperativo, pois estão fundamentadas na divisão de tarefas para o ato de escrever. Assim, esse panorama coloca parte significativa dos chats com uma organização colaborativa do processo de autoria em função das estratégias de escrita.

No que diz respeito aos grupos que adotaram a estratégia de construção integrada, foi possível observar que a produção do texto está vinculada à utilização de diversas habilidades de comunicação colocadas em funcionamento nos chats, corroborando o que sugere a Taxonomia de Habilidades de Aprendizagem Colaborativa. ${ }^{30,31}$ Uma dessas habilidades é a de adição de informações ao contexto, associada a movimentos de condução da escrita, reformulações e oferecimento de esclarecimentos ao parceiro de dupla. Outra habilidade digna de destaque é a condução da conversação, em termos da execução e manutenção da tarefa, como também de motivação durante a realização da mesma, seja a partir da formulação de elogios em termos do trabalho executado pelo parceiro, seja a partir da argumentação frente às discordâncias que emergem.

A prevalência de construção integrada contraria os resultados de algumas inciativas voltadas à investigação dos modos de organização dos estudantes para autoria coletiva. ${ }^{10,14,17,28}$ Tais trabalhos, por exemplo, garantem que os estudantes engajados em atividades de autoria coletiva tendem a operar de maneira mais cooperativa do que colaborativa. Onrubia e Engel, ${ }^{14}$ por exemplo, constataram que dentre as estratégias para autoria coletiva as mais utilizadas entre um grupo de 46 estudantes de graduação em psicologia e psicopedagogia, organizados em grupos de três, quatro e cinco participantes, estão as de construção paralela-divisão estratificada e construção paraleladivisão horizontal. Os autores arrematam que, na maioria das atividades de autoria coletiva, o texto coletivo final é resultado não de uma atividade colaborativa, mas da reunião dos trabalhos individuais. Fato é que sob determinadas condições e contextos, cada investigação resulta em determinadas tendências, seja de caráter colaborativo ou cooperativo. No outro lado desse espectro, por exemplo, há trabalhos que enfatizam o caráter colaborativo e dialógico da autoria coletiva em número significativo de agrupamentos de estudantes. ${ }^{5,6,12}$

A respeito das funções, a Figura 3 mostra a distribuição das mesmas, considerando o número de funções assumidas como também a sua estratégia para autoria.

A Figura 3 mostra que em sete duplas dos chats com construção integrada, os dois integrantes desempenharam as quatro funções. Nas demais, nas quais foi detectado a mesma estratégia, pelo menos

\title{
Exercício das quatro funções
}

Um integrante exerce quatro funções; o outro três

Um integrante exerce as quatro funções; o outro dois

Um integrante exerce três funções; o outro dois

Um integrante exerce duas funções; o outro uma

Cada um exerce uma função

\author{
- Construção integrada \\ * Construção paralela-divisão horizontal
}

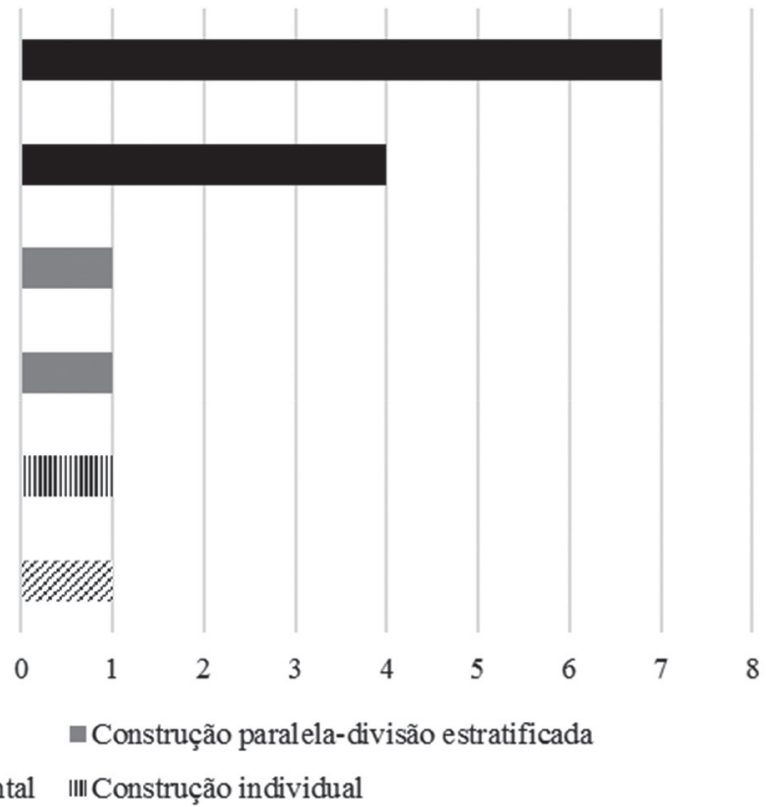

Figura 3. Distribuição das funções, segundo as estratégias por cada dupla 
um dos estudantes exerceu o conjunto de quatro funções, enquanto o parceiro desempenhou três funções. Sobre isso, Saunders ${ }^{29}$ defende que em uma organização colaborativa de atividades de autoria coletiva, espera-se que o grupo de participantes interaja e contribua de forma compartilhada para as funções de planejamento, escrita, revisão e edição, tendo em vista que a produção do texto se dá de forma conjunta e há colaboração em todas as etapas.

Levando em conta o caráter colaborativo, resultado da caracterização daquelas duplas que adotaram a estratégia integrada, é razoável afirmar que, no contexto das funções desempenhadas pelos integrantes e sob a ótica dos Saunders, ${ }^{29}$ os participantes também se organizaram de forma colaborativa. Essa tendência se torna evidente no exercício de todas as funções pelos dois integrantes de cada dupla ou pela interatividade, para aqueles chats nos quais um estudante não exerce uma certa função, mas participa ativamente do processo de autoria, em que o parceiro, por sua vez, desempenha todas as funções.

A Figura 3 também mostra que boa parte das duplas que não adotaram a estratégia integrada também não desempenhou o conjunto das quatro funções. Em apenas uma, na qual foi adotada a estratégia de construção paralela-divisão estratificada, um integrante exerce as quatro funções e o parceiro duas, mas, como mostra a estratégia adotada, tendo o princípio organizacional a divisão do trabalho. Esse cenário fornece subsídios para que os processos de autoria coletiva dessas duplas não sejam caracterizados como colaborativos sob a ótica de Saunders, ${ }^{29}$ mas baseados na cooperação, pois, ou não há o exercício das quatros funções por pelo menos um integrante ou, quando ocorre, esta é guiada pela divisão do trabalho em certas tarefas.

A investigação demonstra que a estratégia de construção integrada se mostra necessária para o exercício de um maior número de funções, o que é reforçado por definição pelo seu caráter interativo, no qual todos participam decisivamente das etapas de construção, ou seja no planejamento, escrita, edição e revisão. Já a respeito das estratégias baseadas na divisão do trabalho, a investigação revela que pelo menos um estudante exerce menos que duas funções, o que é coerente com a natureza cooperativa, pela qual as funções são exercidas de forma complementar ou sob maior responsabilidade de um dos integrantes.

\section{CONSIDERAÇÕES FINAIS}

Este artigo descreve um estudo sobre estratégias e funções assumidas por estudantes de graduação em Química que se envolveram em atividade de autoria coletiva de soluções a estudos de caso com a mediação do eduqui.info. A relevância da iniciativa reside no seu potencial para a promoção de uma aprendizagem com ênfase na escrita e na colaboração, que são elementos fundamentais para o desenvolvimento de habilidades como a comunicação científica e o trabalho em grupo.

A investigação também contribui com a apresentação de importantes indícios analíticos que permitem o alcance de respostas sobre estratégias e funções assumidas pelos estudantes na produção textual em ambiente informatizado. Indícios estes capazes de subsidiar o trabalho de docentes e pesquisadores atuantes em tal vertente.

Embora neste estudo os aprendizes tenham levado a cabo as suas atividades a partir da colaboração, em detrimento da cooperação, não existe intenção em atribuir ao trabalho colaborativo um status mais elevado em relação ao cooperativo, visto que, em determinadas condições, um ou outro pode ser mais veemente buscado pelo professor. De fato, artigos de nossa autoria publicados nesta revista também reportam ações didáticas fortemente baseadas no trabalho cooperativo em sala de aula..$^{32,33}$
Por fim, é necessário destacar a escassez de trabalhos no campo da educação em Química, especialmente no nosso país, que lidam com a questão da inserção das novas tecnologias de informação e comunicação nos ambientes de ensino e aprendizagem,,${ }^{34}$ o que alenta o desejo de que o relato ora apresentado inspire investidas nessa área.

\section{AGRADECIMENTOS}

O presente trabalho foi realizado com apoio da Fundação de Amparo à Pesquisa do Estado de São Paulo (FAPESP/ Processos 13/10610-0 e 12/05437-5), do Conselho Nacional de Desenvolvimento Científico e Tecnológico (CNPq) e da Coordenação de Aperfeiçoamento de Pessoal de Nível Superior - Brasil (CAPES) - Código de Financiamento 001.

\section{REFERÊNCIAS}

1. Zucco, C.; Pessine, F. B. T.; Andrade, J. B.; Quim. Nova 1999, 22, 454.

2. Oliveira, T.; Freire, A.; Carvalho, C.; Azevedo, M.; Fresie, S.; Baptista, M.; Educar 2009, 34, 19.

3. Rice, J. A; IEEE Transactions on Professional Communication 2009, $52,303$.

4. Noel, S.; Robert, J. M.; Computer Supported Cooperative Work 2004, 13,63 .

5. Costa, J. S.; Tese de Doutorado, Universidade Federal do Rio Grande do Sul, Brasil, 2008.

6. Axt, M.; Elias, C. S.; Em Psicologia e educação: multiversos, sentidos, olhares e experiências; Palombini, A. L., Maraschini, C., Carvalho, D. L., Freitas, L. B. L., eds.; Editora UFRGS: Porto Alegre, 2003.

7. Moy, C. L.; Locke, J. R.; Coppola, B. P.; Mcneil, A.; J. Chem. Educ. 2010, 87, 1159 .

8. Pence, L. E.; Pence, H. E.; J. Chem. Educ. 2015, 92, 86.

9. Kristian, K. E. A.; J. Chem. Educ. 2015, 92, 2074.

10. Blau, I.; Caspi, A.; Conference on Instructional Technologies Research: Learning in the Technological era, Ra' anana, Israel, 2009.

11. Tal-Elhasid, E.; Meishar-Tal, H.; Learning in the Technological Era 2007, 127.

12. Elliott III, E. W.; Fraiman, A.; J. Chem. Educ. 2009, 87, 54.

13. Villalta, M. M.; Revista Iberoamericana de Educación Matemática 2007, 9, 73

14. Onrubia, J.; Engel, A.; Computers \& Education 2009, 53, 1256.

15. Barro, M. R.; Veras, L.; Queiroz, S. L.; Quim. Nova 2016, 39, 238.

16. Rick, J.; Guzdial, M.; Computer-Supported Collaborative Learning 2006, 1,89 .

17. Ioannou, A.; Artino, A.; Society for Information Technology and Teacher Education International Conference, Chesapeake, Estados Unidos, 2008.

18. Onrubia J.; Engel A.; International Journal of Computer-Supported Collaborative Learning 2012, 7, 161.

19. Dillenbourg, P.; Hong, F. International Journal of Computer-Supported Collaborative Learning 2008, $3,5$.

20. Martins, A. R.; Axt M.; Informática na Educação: Teoria \& Prática 2004, 7, 39.

21. Figueiredo, F. J. Q.; A aprendizagem colaborativa de línguas, Editora UFG: Goiânia, 2006.

22. Santarosa, L. M. C.; Conforto, D.; Basso, L. D. O.; Revista Brasileira de Informática na Educação 2013, 21, 121.

23. Machado, A. C. T.; $e$-Tec 2009, 2.

24. Dietrich, E. Dissertação de Mestrado, Universidade Federal do Rio Grande do Sul, Brasil, 1996.

25. Souza, N. S.; Cabral, P. F. O.; Queiroz, S. L.; Quim. Nova Esc. 2018, 40, 153. 
26. Sá, L. P.; Queiroz, S. L.; Estudo de casos no ensino de química, Átomo: Campinas, 2009.

27. Queiroz, S. L.; Silva, E. M.; Em Estudos de casos para o ensino de química 1; Queiroz, S. L., Silva, E. M., eds.; Editora CRV: Curitiba, 2017.

28. Lowry, B. P.; Curtis, A.; Lowry, M. R.; Journal of Business Communication 2004, 41, 66.

29. Saunders, W. M.; International Journal of Educational Research 1989 , 13,101 .
30. Soller, A.; Goodman, B.; Linton, F.; Gaimari, R.; Proceedings of $4^{\text {th }}$ International Conference on Intelligent Tutoring Systems, San Antonio, USA, 1998.

31. Cabral, P. F. O.; Souza, N. S.; Queiroz, S. L.; Quim. Nova 2017, 40, 1121.

32. Teodoro, D. L.; Pagotto, J. F.; Motheo, A.J; Queiroz, S. L.; Quim. Nova 2011, 34, 714

33. Massi, L.; Cerrutti, B. M.; Queiroz, S. L.; Quim. Nova 2013, 36, 897.

34. Giordan, M; Quim. Nova Esc. 2015, 37, 154. 